\title{
FRANK NELSON COLE
}

\author{
BY T. S. FISKE
}

Frank Nelson Cole, son of Otis Cole and Frances Maria Pond Cole, was born at Ashland, Massachusetts, September 20, 1861. Prepared for college at the Marlborough (Massachusetts) High School, he was admitted to Harvard in September 1878 and at graduation in 1882 stood second in his class. After studying mathematics for a year in the Graduate School of Harvard University, he was appointed to a traveling fellowship and spent the following two years (1883-1885) at the University of Leipsic, where he was a member of the mathematical seminar of Professor Felix Klein.

Returning to Harvard in 1885 , he was for two years lecturer in the Graduate School. In 1886 he received from Harvard the degrees of A.M. and $\mathrm{Ph} . \mathrm{D}$. In the summer of 1888 he revisited Germany and married Miss Martha Marie Streiff of Hamburg.

In the autumn of 1888 he became instructor in mathematics at the University of Michigan, and a year later was promoted to an assistant professorship. In 1895 he was called to Columbia University as professor of mathematics with assignments to the University Faculty of Pure Science and to the Faculty of Barnard College. For fourteen years (1901-1914) he served on the Committee on Admissions of Barnard College. During three years (1904-1906) he was an examiner in mathematics tor the College Entrance Examination Board.

He was elected Secretary of the American Mathematical Society in 1895, became a member of the editorial staff of the Bulletin in 1898, and succeeded the author of this sketch as editor-in-chief of the Bulletin in 1899. In 1920 he relinquished his administrative and editorial labors for the American Mathematical Society. However, he continued his work in the Columbia University Faculty of Pure Science and at Barnard College.

In the spring of 1926 he applied to Columbia University to be released from active service on September 20,1926, the sixty-fifth anniversary of his birth. Suddenly taken seriously ill he died of heart failure May 26, 1926. He was survived by his wife, two sons, and a daughter.

A picture of Frank Nelson Cole in 1885 after his return from Leipsic is sketched in the following excerpt from an address "Professor Bôcher's Scientific Start in Life" delivered by Professor William Fogg Osgood at a meeting of the Harvard Mathematical Club held February 12, 1925:

"The other course, Mathematics 13, was given by Mr. (at that time not yet Dr.) Frank Nelson Cole, who had just returned from Germany and was aglow with the enthusiasm which Felix Klein inspired in his students. Cole was not the first to give a formal course of lectures at Harvard on the theory of functions of a complex variable, Professor James Mills Peirce having lectured on this subject in the seventies. That presentation was, however, solely from the Cauchy 
standpoint, being founded on the treatise of Briot and Bouquet, Fonctions Elliptiques. Cole brought home with him the geometric treatment which Klein had given in his noted Leipsic lectures of the winter of 1881-1882. Cole also gave a course in Modern Higher Algebra, with its applications to geometry. The enthusiasm which he felt for his subject was contagious. Interesting as were the other courses I have mentioned, they stood as the Old over against the New and of the latter Cole was the apostle. The students felt that he had seen a great light. Nearly all the members of the Department,Professor J. M. Peirce, Dr. B. O. Peirce, and I think, Professor Byerly,-attended his lectures. It was the beginning of a new era in in graduate instruction at Harvard, and mathematics has been taught here in that spirit ever since."

In the publication of scientific papers the most productive period of Professor Cole's life was the seven years (1888-1895) during which he was connected with the University of Michigan. He had previously published three papers, one of them a long critique of Klein's Ikosaeder, in the American Journal of Mathematics. While at Michigan he published eight papers and a translation of the work of Eugen Netto on The Theory of Substitutions. In the period of thirty-one years during which he was connected with Columbia University he published nine scientific papers, over one hundred reports of meetings of the American Mathematical Society, and innumerable unsigned notes containing items of interest to the mathematical community.

From the time of his arrival in New York in 1895, Cole devoted the larger part of his time, thought, and efforts to the administrative and editorial activities of the American Mathematical Society. His greatest and most ab sorbing interest in life seemed to be that the affairs of the American Mathematical Society should be conducted wisely, efficiently, and with good taste. He was tireless in his opposition to anything that seemed to him slovenly, unscholarly, or born of an excess of zeal.

In 1920, upon the conclusion of a quarter of a century of service to the Society, some hundreds of his fellow members joined in presenting him with a purse as a token of their admiration and gratitude. This he turned back to the Society, and upon the recommendation of the Council it was used for the purpose of founding a prize to be known as the Frank Nelson Cole prize in Algebra. At the same time in recognition of his distinguished services volume 27 of the Bulletin (the thirtieth volume counting from the establishment of the Bulletin in 1891) was dedicated to him. His portrait appears as the frontispiece of that volume.

At the meeting of the Mathematical Society held September 9, 1926, the following minute was adopted:

"On the recommendation of its Council, the American Mathematical Society, meeting in Columbus, Ohio, on September 8, 1926, expresses its deep sense of loss in the death of Frank Nelson Cole on May 26, 1926. He was for many years the Society's most active executive officer. From an early date in its history until 1920 when he passed his duties on to others, he ably guided the development of the 
Society. As Secretary from 1895, and as Editor-in-Chief of the Bulletin from 1899, he led the Society from its modest beginnings to a state of solid accomplishment. He exercised his functions with a skill which excited admiration and which gave the American Mathematical Society an established place in the scientific world. When he retired he turned over to his successors a healthy structure that was able to withstand the stresses of the very difficult post-war period.

The Society wishes now to place on record its grateful recognition of his devoted service to the ideals of American Mathematical Science. His memory will remain an inspiration to all who may in the future serve the interests of the Society and the cause of mathematics in America."

In order to realize how valuable and timely was the service Cole rendered to mathematicians by publishing his translation of Netto's Theory of Substitution Groups, one must notice that it was practically the first textbook on the subject in English. European students had easy access to Groups in Serret's Algebre Superieure from the 3rd edition (1866), and in the German edition of Netto's book (1882). Yet no English author had at that date taken up the task of presenting the subject for beginners; if we except seven pages in Chrystal's Algebra, and journal papers by Cayley and Bolza. An additional value attaches to Cole's book, in that it gave Netto opportunity to revise, omit, and recast considerable portions of the German text.

A very definite contribution to group theory is his work on simple groups, in two papers, one with Glover's cooperation. These showed only three simple groups of orders between 200 and 661. Burnside and Dickson later carried the upper boundary to 1000 .

The papers cited below on triad systems and their groups mark an interesting outgrowth of the Netto translation. Debate arose over a matter left indefinite in that book, whether every triad system must have a transitive group. A survey of the literature showed examples to the contrary, one of the two possible triad systems on thirteen elements having a group of order six. The possibility of enumerating all the triad systems on fifteen elements was then discussed, whereupon Miss Cummings developed the earliest examples of incongruent systems exhibiting congruent groups, and extended the number of known systems to twenty-four. Mr. White followed this with a complete synthesis of all having actual groups bringing the number up to forty-four. Cole meantime had begun, but deferred the completion of, an exhaustive discussion of the structure of such systems, based on "interlacings." When he was shown some novel systems, which admit no group of substitutions save the identity, a race began for results. The two others found a way of deriving new systems from old, and had produced thirty-three of this new sort, before Cole finished his investigation showing about fifty such, in addition to those admitting groups. Miss Cummings, applying to all these her speedy method of comparison by "indices," discovered many duplicates. Cole had not overlooked any that were already known, but had found thirty-six "groupless" systems, the last three being entirely new. This brought the whole list up to eighty; and 
Cole's deductive method furnished the climax, the proof that now the list is complete. This was probably the only investigation in which he collaborated with others; and even in this his methods were entirely independent, only the results permitting comparison and control.

The short paper on Kirkman Parades was essentially an extract from this larger work, and served to settle conclusively the "fifteen schoolgirl problem."

\section{List of Professor Cole's Publications}

Reports of Meetings of the American Mathematical Society: this Bulletin, vol. 3, p. 1; vol. 4, pp .1, 87, 175, 291, 415; vol. 5, pp. 1, 113, 217, 325 , 423; vol. 6 , pp. $95,117,267,365$; vol. 7 , pp. 1,113 , 199, 289; vol. 8 , pp. $1,183,367$; vol. 9 , pp. $183,281,393,525$; vol. 10 , pp. 53 , 119, 171, 221, 373 , 485 ; vol. 11 , pp. $111,231,347,461$; vol. 12 , pp. 53 , 107, 223, 325, 423; vol. 13, pp. 55, 153, 261, 315, 423; vol. 14, pp. 53, 157, 247, 351, 407; vol. 15, pp. $157,275,323,419$; vol. 16 , pp. $53,169,281,395,451$; vol. 17 , pp. 61 , $167,277,389,505$; vol. 18 , pp. $51,159,213,327,485$; vol. 19 , pp. 51,163 , $275,387,497$; vol. 20 , pp. 169,283 , 395,507 ; vol. 21 , pp. $57,161,269,373$; 481 ; vol. 22 , pp. $161,263,373,481$; vol. 23 , pp. $57,157,257,299,435$; vol. 24 , pp. $57,169,265,369,465$; vol. 25 , pp. $49,145,433$; vol. 26 , pp. 145, 241, 337, 433; vol. 27 , p. 97.

The potential of a shell bounded by confocal ellipsoidal surfaces, Proceedings of the American Academy of Arts and Sciences, vol. 9 (1883), pp. 226-231.

A contribution to the theory of the general equation of the sixih degree, American Journal of Mathematics, vol. 8 (1885-86), pp. 265-286.

Klein's Ikosaeder, American Journal of Mathematics, vol. 9 (1886-87), pp. 45-61.

On rotations in space of four dimensions, American Journal of Mathematics, vol. 12 (1889-1890), pp. 181-210.

The linear functions of a complex variable, Annals of Mathematics, vol. 5, (1889-90), pp. 121-176.

Simple groups from order 201 to order 500, American Journal of Mathematics, vol. 14 (1891), pp. 378-388.

Review of Felix Klein, Vorlesungen über die Theorie der elliptischen Modulfunctionen, Bulletin of the New York Mathematical Society, vol. 1 (1891-92), p. 105.

Translation of Eugen Netto, The Theory of Substitutions and its Applications to Algebra. Ann Arbor, 1892.

Note on the substitution groups of six, seven, and eight letters, Bulletin of the New York Mathematical Society, vol. 2 (1892-93), pp. 184-190.

The transitive substitution groups of nine letters, Bulletin of the New York Mathematical Society, vol. 2 (1892-93), pp. 250-258.

On groups whose orders are products of three prime factors (with $\mathrm{J} . \mathrm{W}$. Glover), American Journal of Mathematics, vol. 15 (1893), pp. 191-220.

Simple groups as far as order 600, American Journal of Mathematics, vol. 15 (1893), pp. 303-315. 
Review of Charlotte Angas Scott, An Introductory Account of Certain Modern Ideas in Plane Analytical Geometry, Bulletin of this Society, vol. 2 (1895-96), pp. 265-271.

On the factoring of large numbers, Bulletin of this Society, vol. 10 (190304), pp. 134-137.

The groups of order $p^{3} q^{\beta}$, Transactions of this Society, vol. 5 (1904), pp. 214-219.

The triad system of thirteen letters, Transactions of this Society, vol. 14 (1913), pp. 1-5.

Note on solvable quintics, This Bulletin, vol. 21 (1914-15), pp. 462-464.

The complete enumeration of triad systems in fifteen elements (with L. D. Cummings and H. S. White), Proceedings of the National Academy, vol. 3 (1917), pp. 197-199.

Complete classification of the triad systems on fifteen elements (with L. D. Cummings and H. S. White), Memoirs of the National Academy, vol. 14, No. 2 (1919); 89 pp.

Kirkman Parades, Bulletin of this Society, vol. 28 (1922), pp. 435-437.

On simple groups of low order. Bulletin of this Society, vol. 30 (1924), 489-492. 